\title{
About the Challenges in Undergraduate Research Projects: An Explorative Case Study in a Sri Lankan National University
}

\author{
Colombage Ranil Peiris, Sirkku Männikkö Barbutiu and Henrik Hansson \\ Stockholm University \\ Stockholm, Sweden
}

\begin{abstract}
Conducting research and writing a thesis about it is regarded as a distinctive pedagogy (learning through inquiry) within higher education which brings new challenges to all parties involved. To complete a thesis, students should select a problem, make a systematic plan, implement the plan and, finally, write a report of the process and findings. Students do have a supervisor to guide and support them, but it is the student who plays the key role in the whole research process. The present study is a qualitative, explorative case study to understand the challenges related to research projects within undergraduate management degree programmes in a Sri Lankan national University. Data have been collected using interviews and focus group discussions in six-degree programmes, with around 40 participants in total. The study focuses on identifying problematic areas and creating a general picture of why students' research projects are not progressing favourably. Six main challenges were identified: student motivation, student-supervisor relationships, skills and knowledge, students' workload, the structure of the research project course, and resources and ICT tools. These problematic areas are complex and multidimensional. Therefore, further studies are required to truly understand the complex interrelatedness of these areas.
\end{abstract}

Keywords: Undergraduate Research Supervision; Management Education; Student Supervisor Interaction; Sri Lankan Higher Education, Thesis Projects.

\section{Introduction}

The University Grant Commission of Sri Lanka has introduced a new policy including a research component as a compulsory module in all undergraduate programmes in the country (Ministry of Higher Education, 2012, p. 12). Therefore, all undergraduate students should conduct a research project as a requirement. At present, only about $30 \%$ of the students select the research project course as some of the programmes offer the research project as an 
optional course. However, the number of students conducting research will increase considerably now that research has been made obligatory in all degree programmes.

Sri Lankan institutions of higher education will face new challenges due to this new policy as "Learning through inquiry" or research is a particular kind of pedagogy (Panasan \& Nuangchalerm, 2010) where practices range from traditional essays to research-based, inquiry-based, or problem-based inquires (Brew \& Jewell, 2012). The objective of a research-based inquiry is to solve a problem and add new knowledge to the discipline, while project-based inquiry aims at applying existing knowledge in an innovative way to solve a practical problem. Although objectives are slightly different, both approaches follow a similar process which is supervised by one or more supervisors. At the end of the process, students, working in groups or individually, produce a report called thesis or dissertation. Previous research shows that Learning through inquiry is a contested pedagogical approach with a number of challenges for both students and supervisors (Pastel, 2005).

Studies report that learning through inquiry is a stressful, complex, and problematic process (Rowley \& Slack, 2004). Due to its complexity, the research component has adversely affected completion rates and times of degree programmes (Acker, Hill, \& Black, 1994; Hansson, Larsson, \& Wettergren, 2009). Also, when compared with "traditional" courses, learning through inquiry is more problematic than traditional courses (Connell, 1985). Burton \& Steane (2004) argue that completing a thesis is a difficult and stressful time, and most students find that a range of problems arises during their studies. Hansson et al. (2009) discussed these issues and concluded that around 30\% of master's students at a Swedish university failed to finish their thesis.

Students' research projects and theses are challenging to supervisors as well (l'Anson, 2004). Thesis management, academic knowledge and skills, interpersonal relationships, and institutional support have been identified as issues by McMichael (1993). There are different kinds of reasons for this problematic and complex situation. Although there are numerous studies on postgraduate level research work, there is a lack of studies at the undergraduate level. For example, Rowley and Slack (2004) are concerned with the lack of interesting research projects in higher education institutions; urging them to pay more attention to the research process to support the students' learning and ensure the quality of the thesis.

Due to a large number of students conducting research projects in the future, it becomes important to understand how the organisation and design of the research project course can be made optimal to meet the needs of the students so that they can successfully complete their research projects and eventually get their degree. Existing literature shows issues in the research process, but there is a lack of studies about the Sri Lankan context, particularly about undergraduate level theses and the challenges related to the process in the Sri Lankan higher education. Therefore, this study aims to explore issues affecting the research 
process at undergraduate management degree programmes in a Sri Lankan national university.

The aim of the present study is to explore the current practices in student research projects and identify factors that are negatively affecting research projects at undergraduate degree programmes in Sri Lanka. To this point, the following research questions were put forward:

1) What are the current practices in students' research projects?

2) What are the challenges of students' research projects?

\section{Previous studies}

In our literature review, we found that there are numerous studies of postgraduate research projects, but there are only a few studies about undergraduate level research projects, especially in developing countries. In the following section, we will discuss some of the studies that have examined student motivation, student-supervisor relationships, students' workload, lack of resources, knowledge and skills in research, and design of the research course.

Analysis of the general literature in education shows that student motivation is one of the central issues in understanding their academic performance (Adedokun, Dyehouse, Bessenbacher, \& Burgess, 2010; Kember, 2016). Also, in previous studies, a positive and mutually causal relationship between student motivation and student academic performance has been found (Afzal, Ali, Aslam Khan, \& Hamid, 2010; Ayub, 2010; Everaert, Opdecam, \& Maussen, 2017). In the literature of research projects, student motivation is identified as one of the main challenges (Afzal et al., 2010; Pintrich, 2003).

Studies show that students have problems with time management, planning of their studies, coping with their workload, and organising group work (Brew \& Jewell, 2012; Harrison \& Whalley, 2008; M. Todd, Bannister, \& Clegg, 2004; Wenderholm, 2004). All this affects student motivation (M. Todd et al., 2004). Also, previous studies have discussed how the design of the research course may prevent the students from successfully completing the research project (Wenderholm, 2004, p. 74). This suggests that the design of the research course is important. This is because it may support the students in the process (Brown, Lewis, \& Bevan, 2016; M. Todd et al., 2004), as it may also prevent them from the successful completion of their research project.

Another central issue in previous studies is student-supervisor relationships. Hettige (1995 as cited in Perera, 2014, p. 98) highlighted the hierarchical relation and the lack of interaction between Sri Lankan university students and their teachers. Also, Christie and Jurado (2013) report a significant proportion of incidents involving power struggles and a lack of professional and emotional support, as well as poor communication during the research projects. For successful supervision, supervisors need to play multiple roles during the research project (Atkins \& Brown, 2002; Cook, 1980). The roles, responsibilities, and qualifications of effective facilitators remain heavily debated (Mohd Isa, NorJunainah; Jusoh, Ahamd Jazimin; Mohd Razali, 2015). In addition to 
academic advice, students require support and encouragement in order to gain the confidence needed to complete their research projects (M. J. Todd, Smith, \& Bannister, 2006). Students come from diverse social, economic, and personal backgrounds (Morgan, 2013) and they have different learning styles (Prem Ramburuth \& John McCormick, 2001). Therefore, supervisors should be sensitive to these differences between students, (Manathunga, 2007, p. 171) in order to build a functional student-supervisor relationship.

Especially, in developing countries, the lack of resources such as access to literature, computers and the Internet affect on the research projects (Ngozi \& Kayode, 2013; Zenzele, 2010). Studies also show that study and research skills of the students play a central role in the success of research projects. According to Barratt (2004, pp. 220-222), students' problems start with the selection of the topic. They find it difficult to find relevant information, to filter available information, and to use the information. It also seems that they have insufficient subject knowledge. Wenderholm (2004, p. 74) discusses how the students' lack of knowledge prevents progress in research projects. Marker (2006, p. 22) suggests that problem-based learning could be introduced in Sri Lankan higher education to strengthen students' research skills. Perera (2014, p. 71) reported the lack of English language proficiency and difficulties in reading research papers as two important issues in the Sri Lankan higher education context preventing students success.

In conclusion, our literature review shows that there are three key stakeholders students, supervisors, and institutions of higher education - playing central roles in the students' research projects and influencing the success in theses realisation. The relations between these three stakeholders are crucial and intertwined. Specific issues such as student motivation, student-supervisor relationships, access to resources, study and research skills, as well as the design of the research course all seem to be important issues. In our study, we will examine further these relations and how they influence the progress of students' research projects.

\section{Methodology}

The unstudied field of undergraduate students' research projects made us choose explorative case study strategy to answer our research questions. Interviews, focus group discussions, and document analysis have been applied as data collection tools. A set of structured questions was applied in all interviews, and additional clarifying questions were included depending on the responses. Results from the previous studies informed us in the preparation of the questions.

Considering the sensitive relationship between supervisors and students, where the latter is dependent on the former, we decided to address only students who had completed their degree programme recently. Thus, they did not have to fear any negative consequences for criticizing the process or persons involved. In addition, they still had the experience in recent memory. Another strategy to secure anonymity was to ask interviewees to leave out names when talking 
about their experiences. The interviewees were informed of the purpose, and the conditions of the study and their consent forms were collected at the beginning of their interview. All interviews were conducted in Singhalese, the first language of the participants. Later, interviews were translated into English and transcribed by the principal author using a qualitative data analysis software.

\subsection{Case selection and sampling}

A faculty of management studies from a Sri Lankan national university was selected as a case. The faculty offers several management degree programmes. Participants were selected from six departments to bring different views into the discussion (Chmiliar, 2010; Yin, 2003) and to achieve a higher level of trustworthiness. Three focus group discussions were conducted, including both research and project-type courses. The participants ranged between eight and ten in each focus group. Individual interviews were conducted with ten supervisors and nine students who were randomly selected from six degree programmes. Interviews were conducted until the authors felt that data saturation was reached. Table 1 summarises the data collection methods applied in the current study.

Table 1: Number of participants in interviews and focus group discussions

\begin{tabular}{|l|l|}
\hline Number of supervisor interviews & 10 \\
\hline Number of student interviews & 9 \\
\hline Focus group discussions & 3 (total 22 participants) \\
\hline
\end{tabular}

\subsection{Method of data analysis}

We followed Denscombe's (2010, p. 284) suggestions for qualitative data analysis applying grounded theory approach. We used MaxQDA for organising, transcribing, and coding our data. We coded the collected data through careful reading and memo writing. During the coding phase, we focused on issues and challenges highlighted by the participants. Supervisor, student, and course structure related codes emerged from the analysis. These codes were further analysed and grouped by merging similar codes. These groups represent issues and unfavourable situations of the research projects. These are shown as circular shapes in Figure 1. Identified issues and unfavourable situations were further grouped into challenges. The emerged challenges are shown as rectangles in Figure 1. In Then, we cross-checked these challenges with the data and memos. Based on the comparisons, we found links between challenges and issues which are shown as arrows in Figure 1.

Although we followed the principles of grounded theory for the data analysis, we focused our analysis to identifying themes or categories that are most relevant to research objectives (Thomas, 2006, p. 241), since our aim was not to generate a theory. In conclusion, we answered our research questions and made overarching statements about the issues found in the undergraduate research process.

\subsection{Context}

A management faculty in a Sri Lankan national university was selected as the context of this study. This faculty offers four-year management programmes at 
bachelor's level, including several specialised programmes. Although programmes specialise in different disciplines, about one-third of the courses are common for all programmes. For instance, all students follow a common curriculum during the first year and a few other common courses throughout the duration of their degrees. The faculty has formed academic departments based on speciality and lecturers are assigned to those departments. Although students follow different degree programmes, they study with a common team of lecturers.

All programmes are full-time and lectures are scheduled during weekdays in the first three years. As a faculty policy, final year students' lectures are scheduled during evenings and weekends to encourage internships and industry-related activities. Students prefer to meet supervisors in the evenings or at weekends since lectures are scheduled in the evenings and at weekends, and students attend internships or are employed. Evening lectures start at 17.00 or 18.00; hence, students can attend lectures after they finish industry-related activities.

The student research project is offered as a course and also called as the thesis project. A research methodology course runs in the previous semester and covers the theory part. Many of the research projects are supervised by the permanent lecturers and a few projects are supervised by visiting lecturers. The faculty offers 13 degree programmes in total and we studied six of them. A summary of the programmes is given in Table 2. At the time of our study, the student research project was not mandatory. There were two types of studies: the project type study and the research type study. The former is meant to develop an artefact to solve a practical problem, while the latter is meant to answer formulated research questions following a general research methodology. One of the degree programmes offers the research project as a group project (maximum five students), while other programmes offer the research project as an individual project.

Table 2: Comparison of selected degree programmes for the study

\begin{tabular}{|l|l|l|l|l|}
\hline Programme & $\begin{array}{l}\text { Number of } \\
\text { other courses }\end{array}$ & Type of research & Selection mode & Semester \\
\hline Programme1 & 4 courses & $\begin{array}{l}\text { Project-based \& } \\
\text { as a group }\end{array}$ & Compulsory & Fourth year 1st semester \\
\hline Programme2 & 4 courses & Research-based & Optional & Fourth year 2nd semester \\
\hline Programme3 & 3 courses & Research-based & Optional & Fourth year 2nd semester \\
\hline Programme4 & 4 courses & Research-based & Compulsory & Third year 2nd semester \\
\hline Programme5 & 3 courses & Research-based & Optional & Fourth year 2nd semester \\
\hline Programme6 & 4 courses & Research-based & Compulsory & Third year 2nd semester \\
\hline
\end{tabular}

In three of the degree programmes, students start writing a proposal as a part of the methodology course. When students start the research as a course, they draft a research or project proposal and submit it to the research course coordinator. All research courses are organised by a coordinator appointed by the head of the department. The coordinator is responsible for coordinating students and supervisors. In general, the coordinator instructs students to prepare a research proposal and assigns supervisors to students' research projects. 
Sometimes, students contact lecturers before drafting a proposal and ask for help from lecturers to develop an initial research idea. Students then request from the coordinator to assign the lecturer who has already helped them as their supervisors. Thereafter, coordinator assigns supervisors to students in a meeting with lecturers who are eligible to supervise. Research interest, subject knowledge, and seniority will be considered when allocating research projects. Then, students and supervisors meet independently and the supervisors guide students to design and conduct the research project. Although participants and research questions are different there are common activities in all research projects. In general, these activities can be identified as proposal writing, research design, data collection, data analysis, report writing, and conclusions or findings. A special review and feedback sessions are required from supervisors at the end of each of these activities and can therefore be considered as milestones in the research project.

\section{Findings of the study}

In the data analysis, a number of themes were identified as challenging for the students and their supervisors in carrying out and supervising the research projects. Figure 1 summarises the main challenges related to student-supervisor relationships, student motivation and workload, the design of the research project course, educational resources and ICT tools, and the skills and competencies of the students and supervisors. In the following section, we analyse in detail the issues within each challenge.

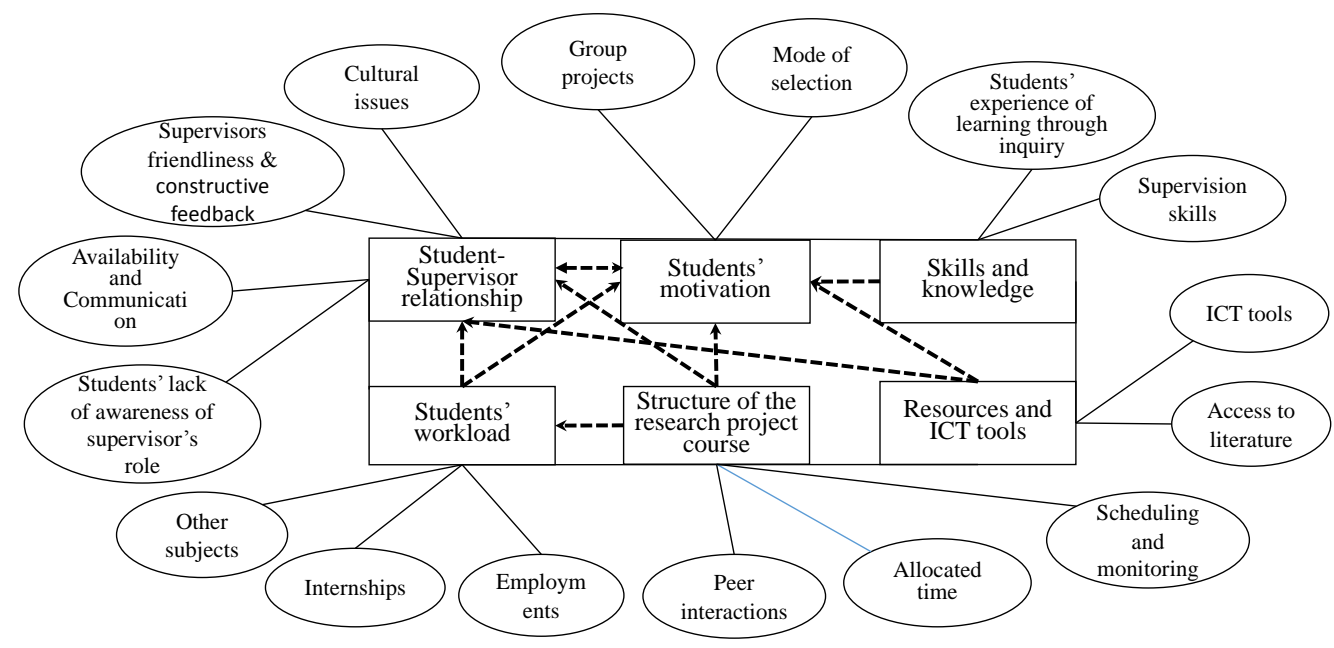

Figure 1. Problematic areas of the research process in undergraduate management programmes in Sri Lanka

\subsection{Student-supervisor relationships}

Within student-supervisor relationships, we identified four major issues: availability and communication, cultural issues, students' lack of awareness of the role of their supervisor, supervisor friendliness and constructive feedback. 


\subsubsection{Availability and communication}

Our data suggest that students and supervisors prefer face-to-face meetings to communicate. It also seems that some of these meetings are not planned beforehand and students try to meet their supervisors ad hoc which is not always successful. One student says, "I want to meet my supervisor but couldn't. I went to his room and just tried to meet the supervisor. Sometimes he wasn't in his room. Then I tried to get an appointment. Sometimes I went to meet my supervisor, but I couldn't meet him". Another student explained, "I went to meet my supervisor, and sometimes he was busy with meetings. [but] I had to go to work; there were such occasions". These quotes also illustrate the difficulty in finding a suitable time for meetings as students often have employment or internship commitments, and consequently they are not free for meetings during weekdays. Supervisors, on their part, do not wish to work during the weekends, which can be the only free time for many working students. It seems that no systematic way of arranging meetings is being applied. Only a few students reported using email or the telephone to arrange appointments with their supervisors. This is somewhat surprising as both students and supervisors have access to the Internet and a Learning Management System (LMS), which provide them with communication tools that would free them from the constraints of time and space.

\subsubsection{Cultural issues}

Sri Lankan society can be described as a hierarchical one which also reflects the Sri Lankan university culture. University teachers represent a group with power over the students and they are treated with great respect by the students. Even if the students feel that they are not happy with their supervisors, they would hesitate to complain. Our data demonstrate this; no student would directly criticise their supervisor. However, we could find some contradictory statements confirming that some students were not happy with their supervisors. Data shows that students are having issues when they want to meet supervisors and receive feedback. We found evidence of supervisors becoming increasingly aware of the problematic situation. One supervisor told us, "This situation is not good for student-supervisor relationships. Also, we talk about [the] open door policy in management; the problem is the gap between student and supervisor. There should be a psychologically open environment". The quote shows that supervisors are trying to change the current situation using a more open policy.

\subsubsection{Students' lack of awareness of the role of their supervisor}

Students in this study seem to have only a vague idea of the role of their supervisor and how to interact or get help from supervisors. Many of the students complained that they have many issues and no one to get help from. They also said that they didn't meet their supervisor because they had no work to show them. One student said, "Then we didn't go to meet the supervisor, we should show some work. We avoid [the] supervisor since we didn't have [work] to show. It is our fault." Another said, "It was a very difficult task since we have to work alone. Many of us didn't have practical knowledge. There wasn't anyone to get assistance from. Our result is low". These statements from the students confirm that students are not aware of the role of a supervisor as someone to provide assistance through the research project. 


\subsubsection{Supervisor friendliness and constructive feedback}

When examining how students and supervisors talk about each other, we found that students expressed appreciation of supervisor support and friendliness. Supervisors, on the other hand, told us about the less friendly side of some supervisors. One supervisor described his successful supervision, "I supervised five students. Four of them were good. If we are friendly with the students, then we can get a good quality [project]". Another supervisor explained the experience, saying, "Supervisor[s] should do their job properly. Sometimes when students meet the supervisor, [they] give unnecessarily big objectives. Then, students will reduce interactions. Otherwise, if we behave friendly then students perform well". Students didn't complain about their supervisors directly, but it is clear that students expect a friendlier attitude and constructive feedback. One student says, "First of all, all students are not equal, [the] supervisor should [be aware of] students' knowledge, also help [us] to improve when we show [them our] progress, the feedback should [given] in a positive way".

\subsection{Student motivation and workload}

Within this section, we will describe the conditions that affect students' motivation and workload. We discuss the implications of the different ways of organising research works and the consequences of students' external engagements such as internships and employments.

\subsubsection{Optional or mandatory research projects}

Students who had the research project as a mandatory component showed more issues than those who had chosen the research project as an optional one. Both students and supervisors involved in the optional research projects were more content with the process; this might be explained by their stronger motivation and interest in conducting the research. Student motivation might also have been strengthened by encouragement from supervisors to publish the research results. One supervisor says, "Yes, I told students to publish their research papers in a conference. Two research projects are at the publishing level. One is not, since there is a language issue. The idea is good". Our data suggest that students who are forced to take the research project course as a mandatory course, who lack interest in research as a whole, and who lack research skills are less likely to be motivated and consequently they experience many problems in completing their research project.

\subsubsection{Group projects}

One of the degree programmes offered the research as a group work project. Our data suggest that group research projects are not functioning properly. One supervisor: says, "We have the issue of honest participation. Therefore, individual projects are good. If there is a method to monitor [the students], group projects can be used. Otherwise, there may be free riders". It seems that if there is a lack of proper monitoring system, the temptation to free ride may be too big. Students expressed their dissatisfaction, saying, "We followed research as a group work [project], it would be good if we could work as a pair, there are free riders when there is a group". Free riding seems to be a problem as there is no particular reporting method to measure or monitor individual contributions. 


\subsubsection{Employment, internships, and other subjects}

Five degree programmes out of the six (5/6) in this study have scheduled the research project to be in the fourth and final year. The final year is usually the busiest year as many students are in employment or do an internship. The university also encourages internships and schedules normal lectures during the evenings and at weekends to allow students to work during the weekdays. In addition to internships, some of the students are working full time to support their economy and to earn an extra qualification.

Both supervisors and students recognise the high workload due to internships or extra jobs. For example, one supervisor said, "We are aware of the internship, but we cannot reproach the students for this because we encourage them to do internships". Students also said they couldn't do the research project properly since they have a lack of time; one student highlighted this, "My supervisor is good, but I couldn't get much help because my interaction was low with my supervisor [compared to] other students. The reason is I didn't have time to meet my supervisor since I did a job". Other courses also increase the workload. One student said, "We had other subjects [in] the final year", and another said, "Actually we just ignored the project and worked for other subjects". All students stated that they did not continue working on the project when they had examinations of other subjects.

\subsection{Educational resources and ICT tools}

In this, we will discuss challenges related to the students' access to educational resources such as literature and ICT tools.

\subsubsection{Access to literature}

Both students and supervisors expressed their concern over the lack of access to relevant research literature. One supervisor explained, "They are not sufficient, even for lecturers. Although there are some resources [that] students don't know [about]. It is not enough to show the library during the orientation programme". According to another supervisor, undergraduates do have sufficient access to the resources but they don't know how to use the resources. Also, we found that the university library allows access to online articles but some students are not aware of how to use these resources. Language is also an issue as students have difficulties understanding research papers written in English. One supervisor explained this situation, "Now, many issues have [been] solved from [the] literature side, we had lack of literature access in the past. Now all my students also have computers. Literature is in English, and some of [the] students are not competent in English. It is difficult to understand [their meaning] when they write in English".

\subsubsection{ICT tools}

The university has invested in ICT in recent years. There are free Wi-Fi and computer labs in university premises. The faculty has given a laptop computer to all lecturers. Although infrastructure exists, ICT tools are rarely used in research project supervision. For example, we found that only a few students and supervisors use ICT tools to share documents and to communicate. Few 
students said they used data analysis software. Other ICT tools to assist students in their writing, such as reference management tools and English language tools, are not being used in any systematic manner by the students.

\subsection{Design of the research project course}

Within the design of a research project course we identified three major issues: Scheduling and monitoring, peer interactions, and allocated time for the research project.

\subsubsection{Scheduling and monitoring}

Properly scheduled and monitored research projects recorded fewer issues than research projects that had a lack of structure. Properly scheduled research courses have specified meetings with a time plan, reporting templates, and in addition, students received enough study information. In general, supervisors monitor their students, but they have not established proper procedures. For instance, there is no formal notification system when students are not achieving milestones. Also, students know there is a lack of monitoring, and there is a lack of motivation to follow the procedures. For example, all degree programs have a policy that students should meet with their supervisors a specific number of times during a research project. But some of the programs were not linked to the activities in the research process. Therefore, students were not motivated, and some of the students met supervisors only to fulfil the mandatory number of meetings. Some students met their supervisors only at the end of the research project; then, they missed opportunities to receive feedback throughout the research process.

\subsubsection{Peer interactions}

During their studies, students are accustomed to peer-collaboration. They have tutorial classes which encourage peer-collaboration. In addition, Sri Lankan universities have a popular informal peer-collaboration method called "Kuppi" sessions. A Kuppi session can be described as a self-organised small group discussion led by one of the students. In the majority of degree programmes, the research project is offered as an individual project, which reduces possibility of peer interaction. Formally, students were not aware of other students' research projects until they presented in the midterm seminar or at the final presentation. As students reported in our study, there is a lack of formal and informal methods of receiving assistance, which is the reason they feel isolated during their research projects.

\subsubsection{Allocated time for the research project}

The research project is offered as one-semester course. Although a semester includes half a year (26 weeks), there are only 13 weeks for academic activities (after deducting vacation time, study leaves, and examination periods). According to both supervisors and students, 13 weeks is not enough to conduct a research project. Many supervisors and students commented about the time management being an obstacle. For example, the midterm examination interrupts the research project because the students will use project time for preparations for the exams. There are practical issues to consider when extending the time of the research project. Especially when the research project 
is offered in the final semester of the final year, the research should be completed in time so that the result of the whole degree programme can be issued. There are two programmes where the research projects are directly linked to the research methodology course. In these programmes, students initiate the research proposal in a previous semester as part of the research methodology course. They will prepare a research proposal, and they can use it as the design of the research project. Therefore, students will have a more specific proposal when they start the research project, and they have more time to complete the course as a whole.

\subsection{Skills and competencies of the students and supervisors}

Within this section, we will discuss students' experiences in learning through inquiry and supervisors' competence in providing support for students in their research works.

\subsubsection{Experience of learning through inquiry}

In research projects, the university introduces a new kind of pedagogy to the students, something they are unfamiliar with after having been subject to more traditional, teacher-centred pedagogies since both their primary and secondary education and their other courses at the university. Both students and supervisors recognise the lack of knowledge, of skills, and competencies of conducting research which affects the research projects negatively. Even though students have followed a research methodology course, it seems that it has not been enough. One supervisor explained this situation, saying, "We should create a research environment, how to go forward doing a self-study. We should avoid bottle-feeding, and then we can tell [them] how to do research". Another supervisor said, "Research methodology knowledge and English research skills are essential. Students have [a] lack of these skills. If we can improve them, then we can go forward". The same supervisor highlighted his evaluation of students' research skills, saying, "The majority of students don't have research skills, I am telling it without fear and based on my 20 years' experience". Students also explained their lack of research experience, "We didn't have a [chance to] practice research until the final year. We didn't have prior experience". It seems that students are not able to act independently, although they are expected to carry out an independent study, due to the lack of research skills.

\subsubsection{Supervisors' supervision skills}

It is not only students; some supervisors also lack research methodology knowledge. For example, one supervisor explained that there are lecturers who have taken courses neither in research methodology nor in supervision. Some supervisors who have recently joined the university lack experience in research project supervising. Therefore, supervisors have difficulties understanding the issues that students are facing when they conduct research projects. 


\section{Discussion}

In our examination of the different degree programmes and the current practices in the students' research projects; we found a number of challenges that influence the research project process in a negative manner (see Figure 1). These challenges are related to the organisation and design of the research project courses, but also to the student-supervisor interactions, students' work and life situations, their motivation, as well as their skills and competencies, all of which play a central role in the success or failure of a research project. Our interview data suggest that student motivation and the student-supervisor relationship are the most crucial factors influencing the progress of students' research projects. Although these factors are more influential than others, both of them depend on the design of the research project course. Therefore, the design of the course can be regarded as a frame for the students' research projects, thus influencing both student motivation and student-supervisor relationships.

\subsection{Student motivation}

According to both this and previous studies, student motivation is a key challenge in research projects. In general, student motivation is related to multiple factors (Afzal et al., 2010; Pintrich, 2003), as illustrated in Figure 1. Among these factors, the design of the research course and student-supervisor relationships are considered as key factors. Our data show that programmes, where a clear structure of scheduled meetings are provided and where the research project course is linked to the research methodology course, are experienced more positively by the students. This suggests that students are motivated when there is a clear structure that guides and monitors the research project. Todd, Bannister, and Clegg's (2004, p. 344) findings confirm a similar relationship. We also found that in programmes with no structure, students were less motivated, something also supported by previous studies (Koeller, 2005; M. Todd et al., 2004).

Also, we found that student motivation is low when the research projects are a mandatory course or are conducted through group projects because they often lack both genuine interest and the research skills necessary to complete the course. Students who select research projects as an optional course seem to be motivated and confident in their research skills. Therefore, students who follow the research project course as an optional module are more successful and face fewer issues compared to others. Besides, we found that students find group projects unappealing as free riding is possible due to a lack of proper monitoring. A similar conclusion was drawn by Tan (2007, p. 271), who argues that a lack of support from group members demotivated students in group work research projects.

The new government policy regarding research projects as a mandatory component in all undergraduate programmes create a new challenge for universities: how to motivate all students to carry out a research project. In the future, we may also see an increased number of group projects as a way to address the increased demand for supervision. This would then call for new monitoring practices in order to discourage the free riding that often takes place 
in present-day group projects.

Students' life situations and the resources available to them are also related to student motivation. For example, we found that students' high workload affects their motivation, which is supported by previous studies (Brew \& Jewell, 2012; Harrison \& Whalley, 2008; Wenderholm, 2004). Students give priority to courses with a schedule and regular activities and are thus less motivated to work on the research projects unless there is a clear structure. The lack of resources is a common issue in many developing countries (Ngozi \& Kayode, 2013; Zenzele, 2010), which is also the case in Sri Lanka. This affects student motivation negatively. In addition to the limited availability of resources, students seem to lack an awareness of how to access the resources available to them. Further, we found that the university has implemented ICT infrastructure but these ICT tools are not used in research project activities. For example, we noted that electronic communication tools were rarely used for student-supervisor interaction, even though students have problems of finding time to meet their supervisors face-toface. Student motivation is also affected by their research skills. Students are not motivated when they lack the necessary skills to complete research project activities. We found that a lack of inquiry-based pedagogy (Markar, 2006, p. 22), which may support research projects in order to prepare students for research projects.

Supervisors need to play multiple roles during the research project (Hewagamage, Wikramanayake, Karunaratne, \& Arunasalam, 2012; Keogh, 2006) and they need to be sensitive to differences between students, their learning styles, and how they approach their work (Manathunga, 2007, p. 171). Consequently, supervisors should, in addition to subject knowledge, be competent in interpersonal skills. Many present-day supervisors are senior lecturers with sufficient experience, but there will be a shortage of experienced lecturers when the research projects area compulsory module and the numbers of students are increasing. Therefore, it is important that junior lecturers are provided with relevant competence development which helps them to prepare for the task of supervision.

\subsection{Student-supervisor relationships}

We found the student-supervisor relationship to be another central issue that influences the students' research projects. As the data show, the faculty has scheduled lectures during the evenings and at weekends to encourage internships. In addition to internships, there is a trend that some students are working full-time during the final year, when many research projects are scheduled. Therefore, students these students are not at the university during general working hours. The common method of student-supervisor interaction is face-to-face meetings. There is then a challenge to match available times for student-supervisor meetings. As a result, student-supervisor interaction is very low in most research projects.

Also, the hierarchical Sri Lankan culture defines the student-supervisor relationship in a way that may prevent the beneficial interaction required in a 
quest for knowledge. Our findings confirm previous research which reports on the social distance between university students and their teachers and the subsequent lack of interaction (Hettige (1995) cited by Perera, 2014, p. 98). Student-supervisor relationships are very much steered by the supervisor's behaviour, how friendly they are, and the kind of feedback they are providing. Even though students did not openly criticise supervisors, it became clear during the interviews that constructive supervisors were more popular. We discovered that student-supervisor relationships were limited due to students' misconceptions of the role of their supervisor. A supervisor's role is to guide students and help when they have problems. However, many students consider supervisors as examiners of their work. They prefer to meet supervisors only if they have some completed work to show. Therefore, students are reluctant to meet supervisors even if they are having problems in the research project. As the research indisputably indicates the importance of student - supervisor interaction in students' research (Chabaya, Chiome, \& Chabaya, 2009; Kam, 1997; Lekamge, Karunanayka, Ariyarathne, Kugamoorthy, \& Perera, 2012; Ngozi \& Kayode, 2013; Styles \& Radloff, 2001), it is worrying to discover that the situation in Sri Lankan universities still needs a lot of improvement. Higher education is clearly in need of competency development for supervisors in the form of courses and workshops where the issues of supervision can be discussed in a collegial manner.

The student-supervisor relationship is also affected by other factors, the design of the research course being the most critical one. Research courses with a clear structure and regular monitoring show a stronger student-supervisor relationship. Student-supervisor relationships and student motivation are interrelated: students with a higher level of motivation showed a stronger relationship with supervisors and vice versa.

ICT tools are rarely used for student-supervisor interaction, even though students and supervisors have problems arranging face-to-face meetings. Therefore, student-supervisor interactions are limited since they are only able to meet a few times during the research project. It is worth to state here that students showed a positive attitude towards the use of digital technologies as a solution that can increase the student-supervisor relationship. But, the introducing ICT is one of the main challenges since it modifies the forms of interaction (Villarruel, Lima, Rivera, \& Morán, 2017). Also, students' workload prevents students and supervisors from regular meeting.

\subsection{The design of the research course}

As mentioned earlier in Sections 5.1 and 5.2, the design of the research project course is a key factor. This is because it affects student motivation and studentsupervisor relationships. Data show that many students are not able to properly manage their time with research activities and often waste time, especially when there is a lack of proper structure and no implemented monitoring system. As we noted, there is a trend of students postponing research project activities when the workload is high or when the research course is not well-structured. As Todd et al. (2004, p. 342) report, this is a common issue and if students are 
not genuinely interested in the project, they do not spend the allocated time on the research project but do other things. Therefore, students get stressed at the end of the semester which affects the quality of the research project. Students should regularly engage in the research project to produce a quality thesis. As we discussed in Sections 5.1 and 5.2, research courses with a clear structure and regular monitoring motivate students to engage in research project activities. A structured research course enhances the quality of undergraduate research project. Brown et al. (2016) and Koeller (2005) also highlighted a similar effect of the design of research course on undergraduate research projects. In general, Sri Lankan universities design normal courses with peer interactions. In previous studies, peer interactions have been highlighted as a method that helps students (M. Todd et al., 2004, p. 344) and appreciated by some of the students (Aghaee \& Hansson, 2013, p. 199). However, we found that no research project courses had included peer collaboration.

\subsection{Limitations}

As a common practice of research, not every issue can be probed in a single study ( Corbin \& Strauss, 2008 as cited in Bakar, 2015). Hence in the current study, we focused the challenges faced by students and supervisors in undergraduate research projects. The study included only a faculty which considered as a typical case, and we suggest further studies including multiple cases. From the selected case, we interviewed only supervisors and lectures from six departments, and when we select students we included only students who recently finished the research project. We assume it will help them to freely talk about their experience since they already received the result. Therefore, sometimes students' may have forgotten some information. Also, the main author has been teaching in Sri Lankan universities during the last 14 years which gives him an insider perspective to the area of the study. The insider perspective may provide deeper insights and easier access to the research field. At the same time, it puts the researcher in a double position where colleagues and students might be prevented to express their genuine feelings and experiences.

\subsection{Conclusion}

In this study, we found six main challenges in undergraduate research projects and these challenges are: student motivation, student-supervisor relationships, the design of the research project course, skills and knowledge, students' workload, and resources and ICT tools. These challenges are interrelated. From these six challenges, student-supervisor relationship and design of the research project course are central issues and directly relate to students' motivation. A close student-supervisor relationship will enhance the students' motivation and encourage students to engage in research project activities even when they have a high workload. And also, if students are motivated it will lead to a close student-supervisor relationship. The design of the research courses where a structure with pre-scheduled meetings is included and also motivate students and will enhance the student-supervisor relationship. The use of ICT tools also may affect the students' motivation and student-supervisor relationship. If students are familiar with learning through inquiry, it also will increase the students' motivation. 


\subsection{Future research}

Because the challenges are intertwined, further studies are required to understand the dynamics of the student-supervisor relationships related to student motivation and the design of the research course. Further, we found that there is a lack of theory-based studies that focus the learning environment of the research projects. Therefore, we suggest studying the theoretical assumptions of the learning through research as pedagogy and understanding the characterises of supporting learning environments. Also, we suggest studying the effects of these challenges and sources in different contexts.

\section{References}

Acker, S., Hill, T., \& Black, E. (1994). Thesis supervision in the social sciences: Managed or negotiated? Higher Education, 28(4), 483-498. http:/ / doi.org/10.1007/BF01383939

Adedokun, O. a., Dyehouse, M., Bessenbacher, A., \& Burgess, W. D. (2010). Exploring Faculty Perceptions of the Benefits and Challenges of Mentoring Undergraduate Research. Annual Meeting of the American Educational Research Association, 1-11. Retrieved from http://eric.ed.gov/?id=ED509729

Afzal, H., Ali, I., Aslam Khan, M., \& Hamid, K. (2010). A Study of University Students' Motivation and Its Relationship with Their Academic Performance. International Journal of Business and Management, 5(4), 80-88. http://doi.org/10.5539/ijbm.v5n4p80

Aghaee, N., \& Hansson, H. (2013). Peer Portal: Quality enhancement in thesis writing using self-managed peer review on a mass scale. The International Review of Research in Open and Distributed Learning, 14(1), 186-203. http:/ / doi.org/10.19173/irrodl.v14i1.1394

Atkins, M., \& Brown, G. (2002). Effective Teaching in Higher Education. London ; New York: Routledge. Retrieved from https:/ / books.google.se/books?id=jrWJAgAAQBAJ

Ayub, N. (2010). Effect of Intrinsic and Extrinsic Motivation on Academic Performance. Pakistan Business Review, (November), 363-372.

Bakar, A. (2015). A Grounded Theory Study of Learning Patterns of Asian Students in Higher Education. International Journal of Learning, Teaching and Educational Research, 14(1), 20-38.

Barratt, A. (2004). The Dissertation: What Sort of Animal Is It and How Might It Be Better Trained? British Journal of Theological Education, 14(2), 208-228. http://doi.org/10.1558/jate.v14i2.208

Brew, A., \& Jewell, E. (2012). Enhancing quality learning through experiences of research-based learning: implications for academic development. International Journal for Academic Development, 17(1), 47-58. http:/ / doi.org/10.1080/1360144X.2011.586461

Brown, A. M., Lewis, S. N., \& Bevan, D. R. (2016). Development of a structured undergraduate research experience: Framework and implications. Biochemistry and Molecular Biology Education, 44(5), 463-474. http:// doi.org/10.1002/bmb.20975

Burton, S., \& Steane, P. (2004). Surviving your thesis. In Physics World (pp. 46-47). Retrieved from http:/ / books.google.com/books?hl=en\&lr=\&id=kbKKbX6Pn0kC\&oi=fnd\&pg=PP $1 \& d q=$ Surviving + your+thesis\&ots=wtLMBubLFm\&sig=_Qels9KB963HiKrxxqbzH mbWGno

Chabaya, O., Chiome, C., \& Chabaya, R. (2009). Students' failure to submit research projects on time: a case study from Masvingo Regional Centre at Zimbabwe Open University. Open Learning: The Journal of Open and Distance Learning, 24(3), 211-221. 
http://doi.org/10.1080/02680510903201615

Chmiliar, L. (2010). Multiple-Case Designs. Encyclopedia of Case Study Research. http://doi.org/http://dx.doi.org/10.4135/9781412957397

Christie, M., \& Jurado, R. (2013). Using Communicative Action Theory to Analyse Relationships Between Supervisors and Phd Students in a Technical University in Sweden. Högre Utbildning, 3(3), 187-197. Retrieved from http://pjos.org/ojs/index.php/hus/article/view/5650

Connell, R. (1985). How to Supervise a Ph. D. Vestes. Retrieved from http:/ / www.eric.ed.gov/ERICWebPortal/recordDetail?accno=EJ333265

Cook, M. C. F. (1980). The role of the academic supervisor for undergraduate dissertations in science and science-related subjects. Studies in Higher Education, 5(2), 173-185. http:// doi.org/10.1080/03075078012331377206

Denscombe, M. (2010). The good research guide for small-scale social research projects. Psychological Science (Vol. 86178035). Retrieved from http://www.amazon.co.uk/dp/0335220223

Everaert, P., Opdecam, E., \& Maussen, S. (2017). The relationship between motivation, learning approaches, academic performance and time spent. Accounting Education, 26(1), 78-107. http:// doi.org/10.1080/09639284.2016.1274911

Hansson, H., Larsson, K., \& Wettergren, G. (2009). Open and flexible ICT-support for student thesis production-design concept for the future. In The Cambridge International Conference on Open and Distance Learning 2009 (p. 197). Open University Press. Retrieved from http:/ / www.cambridgedistanceeducation.org.uk/CambridgeConferenceMainPap er2009.pdf\#page $=197$

Harrison, M. E., \& Whalley, W. B. (2008). Undertaking a Dissertation from Start to Finish: The Process and Product. Journal of Geography in Higher Education, 32(3), 401-418. http://doi.org/10.1080/03098260701731173

Hewagamage, K. P., Wikramanayake, G. N., Karunaratne, D. ., \& Arunasalam, S. (2012). Outcome and Challenges of Guiding Large Number of Distance Learning Students to Complete their Final Year Projects Successfully (pp. 345-362). Osaka, Japan: The International Academic Forum.

Kam, B. H. (1997). Style and Quality in Research Supervision : The Supervisor Dependency Factor. Higher Education, 34(1), 81-103. http://doi.org/10.1023/a:1002946922952

Kember, D. (2016). Understanding the Nature of Motivation and Motivating Students through Teaching and Learning in Higher Education. Cambridge University Press. Singapore: Springer Singapore. http:/ / doi.org/10.1007/978-981-287-883-0

Keogh, K. Mac. (2006). Supervising undergraduate research using online and peer supervision. In M. Huba (Ed.), 7th International Virtual University Conference, (pp. 19-24). Bratislava: Technical University Bratislava: Bratislava. Retrieved from http://doras.dcu.ie/82/

Koeller, A. (2005). Experiences with student research at a primarily undergraduate institution. Journal of Computing Sciences in Colleges, 20(3), 181-187.

l'Anson, R. a. (2004). Undergraduate Research Projects and Dissertations: issues of topic selection, access and data collection amongst tourism management students. The Journal of Hospitality Leisure Sport and Tourism, 3(1), 19-32. http://doi.org/10.3794/johlste.31.54

Lekamge, D., Karunanayka, S., Ariyarathne, A., Kugamoorthy, S., \& Perera, R. (2012). improving supervisors' supprot for completion of dissertations. In Annual academic sessions, Open University of Sri Lanka (pp. 60-63).

Manathunga, C. (2007). Supervision as mentoring: the role of power and boundary crossing. Studies in Continuing Education, 29(2), 207-221.

http://doi.org/10.1080/01580370701424650 
Markar, M. (2006). Problem-based Learning - is it right for Sri Lanka? APERA Conference 2006, (November), 1-24.

McMichael, P. (1993). Starting up as supervisors: The perceptions of newcomers in postgraduate supervision in Australia and Sri Lanka. Studies in Higher Education, 18(1), 15-26. http:// doi.org/10.1080/03075079312331382428

Ministry of Higher Education. (2012). Sri Lanka Qualifications Framework. Retrieved from https://www.ilo.org/dyn/youthpol/en/equest.fileutils.dochandle?p_uploaded_fi le_id $=232$

Mohd Isa, NorJunainah; Jusoh, Ahamd Jazimin; Mohd Razali, M. M. S. (2015). ProblemBased Learning: Mandatory Personal Qualities of Effective Facilitators. International Journey of Learning, Teaching and Educational Research, 13(October), 88-96.

Morgan, M. (2013). Supporting Student Diversity in Higher Education: A Practical Guide. Taylor \& Francis. Retrieved from https:/ / books.google.se/books?id=udocAAAAQBAJ

Ngozi, A., \& Kayode, O. G. (2013). Variables Attributed to Delay in Thesis Completion by Postgraduate Students. Journal of Emerging Trends in Educational Research and Policy Studies, 5(1), 6-13. Retrieved from https://journals.co.za/content/sl_jeteraps/5/1/EJC150461

Panasan, M., \& Nuangchalerm, P. (2010). Learning Outcomes of Project-Based and Inquiry-Based Learning Activities. Journal of Social Sciences ( ..., 6(2), 252-255.

Pastel, R. (2005). Integrating science and research in a HCI design course. ACM SIGCSE Bulletin, 37(1), 31. http://doi.org/10.1145/1047124.1047371

Perera, M. A. N. R. (2014). Problems faced by undergraduates in the learning environment: some evidences from a Sri Lanka university. Sri Lanka Journal of Advanced Social Studies, 3(1), 77-100. http://doi.org/10.4038/sljass.v3i1.7129

Pintrich, P. R. (2003). A Motivational Science Perspective on the Role of Student Motivation in Learning and Teaching Contexts. Journal of Educational Psychology, 95(4), 667-686. http://doi.org/10.1037/0022-0663.95.4.667

Prem Ramburuth, author, \& John McCormick, A. (2001). Learning Diversity in Higher Education: A Comparative Study of Asian International and Australian Students. Higher Education $V O$ - 42, (3), 333. Retrieved from https://ezp.sub.su.se/login?url=http:// search.ebscohost.com/login.aspx?direct=t rue $\& \mathrm{db}=$ edsjsr $\& A N=$ edsjsr.3448000\&site $=$ eds-live \&scope $=$ site

Rowley, J., \& Slack, F. (2004). What is the future for undergraduate dissertations? Education + Training, 46(4), 176-181. http://doi.org/10.1108/00400910410543964

Styles, I., \& Radloff, A. (2001). The Synergistic Thesis: Student and supervisor perspectives. Journal of Further and Higher Education, 25(1), 97-106. http://doi.org/10.1080/03098770020030533

Tan, E. B. (2007). Research Experiences of Undergraduate Students at a Comprehensive University. International Journal of Teaching and Learning in Higher Education, 19(3), 205-215. Retrieved from http:/ / login.ezproxy.library.ualberta.ca/login?url=http:// search.ebscohost.com/1 ogin.aspx?direct=true\&db=eric\&AN=EJ901294\&site=ehost-live\&scope=site

Thomas, D. R. (2006). A General Inductive Approach for Analyzing Qualitative Evaluation Data. American Journal of Evaluation, 27(2), 237-246. http://doi.org/10.1177/1098214005283748

Todd, M., Bannister, P., \& Clegg, S. (2004). Independent inquiry and the undergraduate dissertation: perceptions and experiences of final-year social science students. Assessment \& Evaluation in Higher Education, 29(3), 335-355. http://doi.org/10.1080/0260293042000188285

Todd, M. J., Smith, K., \& Bannister, P. (2006). Supervising a social science undergraduate dissertation: staff experiences and perceptions. Teaching in Higher Education, 11(2), 161-173. http://doi.org/10.1080/13562510500527693 
Villarruel, J. I. B., Lima, M. G. B., Rivera, R. N., \& Morán, J. M. B. (2017). The use of Social Networks by the Students of a Mexican Public University. International Journal of Learning, Teaching and Educational Research, 16(10), 132-148. http://doi.org/10.26803/ijlter.16.10.10

Wenderholm, E. (2004). Challenges and the elements of success in undergraduate research. 9th Annual Conference on Innovation and Technology in Computer Science Education (ITiCSE), Annual Joi(4), 73-75. http://doi.org/10.1145/1041624.1041661

Yin, R. K. (2003). Case Study Research: Design and Methods (3rd ed.). Thousand Oak CA: SAGE Publications. Retrieved from http:/ / books.google.se/ books?id=45ADMg9AA7YC

Zenzele, W. (2010). Factors Affecting Completion of Research Projects by Students: A study of Three Zimbabwe Open University Regions. Zimbabwe International Journal of Open \& Distance Learning, 1(1). Retrieved from http://researchdatabase.ac.zw/73/ 